\title{
Reproduction and vision in rats maintained on a retinol-free diet containing 3-dehydroretinol (vitamin $\mathbf{A}_{2}$ )
}

\author{
By J. McC. HOWELL \\ Department of Veterinary Pathology \\ AND J. N. THOMPSON AND G. A. J. PITT \\ Department of Biochemistry, University of Liverpool
}

(Received I 5 August I966-Accepted 3 I October 1966)

\begin{abstract}
1. Seventeen hooded female rats were given from weaning a retinol-free diet containing methyl retinoate. When 105 days old they were mated with normal bucks.

2. Six of these rats were subsequently given dietary supplements of $100 \mu \mathrm{g}$ retinol daily and another six were given $100 \mu \mathrm{g} 3$-dehydroretinol daily. All twelve rats had litters.

3. The five rats that received only methyl retinoate during pregnancy resorbed their foetuses.

4. One of the litters from the female rats given 3-dehydroretinol consisted of six male pups. These young rats had never had access to retinol. They were maintained on a retinol-free diet supplemented with methyl retinoate. Two of these rats were given daily supplements of 3-dehydroretinol and another pair were given daily an equal amount of retinol.

5. The six rats were killed when 195 days old. The testes and the retina of the rats given either 3-dehydroretinol or retinol were normal. The testes and the retina of the rats given methyl retinoate only were degenerate.
\end{abstract}

It has been shown that the biological properties of retinoic acid differ from those of retinol; retinoic acid maintains growth in rats but neither vision (Dowling \& Wald, I960) nor reproduction (Thompson, Howell \& Pitt, I964). It is of interest therefore to examine whether other substances, known to replace retinol in the maintenance of growth and general health, can fulfil the special requirements of reproduction and vision.

In tissues of certain freshwater fishes, retinol is accompanied, and to some extent replaced, by 3-dehydroretinol. In rats 3-dehydroretinol is known to maintain growth and health (Shantz, 1948; Shantz \& Brinkman, 1950; Sundaresan \& Cama, I96r).

When dietary retinol is replaced by sources of 3 -dehydroretinol the latter is gradually substituted for the former in the liver, and, within the limitations of analytical methods, there is no indication of in vivo reduction of 3 -dehydroretinol to retinol (Shantz \& Brinkman, 1950). However, complete replacement of retinol by 3 -dehydroretinol in the rat has been claimed to be a very slow process because of tenacious retention of traces of retinol (Shantz, Embree, Hodge \& Wills, 1946).

There is evidence to suggest that the aldehyde, 3 -dehydroretinal, can replace retinal in the visual role of vitamin A by combining with opsin to form a new visual pigment, porphyropsin. This synthesis can take place in vitro (Wald, 1953) and evidence has been presented for its occurrence in vivo in the rat (Shantz et al. 1946) and in man (Millard \& McCann, 1949).

During attempts to breed from rats fed on retinol-free diets containing 3-dehydroretinol, litters were obtained but the mothers failed to rear their young (Shantz et al. 
I946). The authors suggested that 3 -dehydroretinol might be unable to replace retinol in some aspects of reproduction; however no control animals given supplements of retinol were included in these experiments.

The experiments described below demonstrate conclusively the ability of crystalline all-trans 3-dehydroretinol (RO 4-3791/1 from S. A. F. Hoffman-La Roche and Co., A. G. , Basle, Switzerland) to prevent the characteristic visual and reproductive abnormalities which occur in rats fed on vitamin A-deficient diets with or without retinoic acid.

\section{EXPERIMENTAL}

\section{Animals and diet}

Hooded rats from the closed colony maintained in the Biochemistry Department, the University of Liverpool, were used. The methods employed to study the course of pregnancy in the rat were as described previously (Thompson et al. 1964). The basic retinol-free diet was diet II of Thompson et al. (1964) either as formulated or containing methyl retinoate ( $1 \circ \mu \mathrm{g} / \mathrm{g}$ diet).

\section{Histological methods}

Organs were fixed immediately after the animals were killed. Tissues of the reproductive tract were fixed in Bouin's fluid and embedded in paraffin wax, sections were cut at $4 \mu \mathrm{m}$ and stained with haematoxylin and eosin. Eyes were fixed in Zenker's fluid, embedded in nitrocellulose of low viscosity, and sections were cut at $12 \mu \mathrm{m}$ and stained with haematoxylin and eosin.

RESULTS

\section{Reproduction in females}

Female rats were reared from weaning on the retinol-free diet containing methyl retinoate. When 105 days old, seventeen were successfully mated with normal bucks. Six of the pregnant rats were given supplements of retinol and six were given 3 -dehydroretinol (100 $\mu \mathrm{g}$ daily) in each instance, and the remaining five continued on the basal diet. All twelve rats given supplements had litters. Seven litters were successfully weaned and four of these were from the females given 3 -dehydroretinol. The five rats that received only methyl retinoate during pregnancy showed heavy vaginal bleeding and resorbed their foetuses, as described previously (Howell, Thompson \& Pitt, 1964).

\section{Vision and reproduction in males}

One of the litters obtained from the female rats given 3-dehydroretinol consisted of six male pups. These animals had thus not had access, even in utero, to trace amounts of retinol. They were reared on the retinol-free diet supplemented with methyl retinoate and used in further experiments. Commencing when they were 6 weeks old, four of these rats were given daily supplements: two were given 3-dehydroretinol (equivalent to $100 \mu \mathrm{g} /$ day) and another pair were given an equal amount of retinol. The remaining pair received only the diet supplemented with methyl retinoate. The rats were killed when 195 days old and the tissues were taken for examination. 
The testes from the rats given either retinol or 3-dehydroretinol were found to be of normal size and weight (Table I) and complete spermatogenesis was observed in almost all the tubules: those from the rats given methyl retinoate only were small in size (Table I) and the germinal epithelium showed the severe degenerative changes previously described in such rats (Howell, Thompson \& Pitt, I963). The retinas from the rats supplemented with either retinol or 3 -dehydroretinol did not have detectable abnormalities (Pl. I a). Those from the rats given only methyl retinoate had lost the rod-cone layer, and the number of nuclei in the outer nuclear layer was reduced. These changes were particularly marked over the central area of the retina ( $\mathrm{Pl}$. $\mathrm{I} b$ ). This change is similar to that previously described in retinol-depleted rats by Dowling \& Wald (1960).

Table 1. Weights ( $m g$ ) of testes from six individual litter-mate rats given a vitamin A-free diet containing methyl retinoate, with or without supplements of retinol or 3-dehydroretinol

$\begin{array}{cc}\begin{array}{c}\text { Rat } \\ \text { I }\end{array} \\ \text { Rat } \\ \text { I } 409 & 2 \\ 1775 & \text { I225 } \\ & \text { I327 }\end{array}$

\begin{tabular}{|c|c|}
\hline \multicolumn{2}{|c|}{$\begin{array}{l}\text { 3-Dehydroretinol } \\
\text { supplement }\end{array}$} \\
\hline Rat & Rat \\
\hline 3 & 4 \\
\hline 1658 & $167^{\circ}$ \\
\hline 1338 & 1249 \\
\hline
\end{tabular}

\begin{tabular}{cc} 
No supplement \\
\hline Rat & Rat \\
5 & 6 \\
483 & 466 \\
$67 \mathrm{I}$ & 423
\end{tabular}

\section{DISCUSSION}

Retinoic acid is active in maintaining growth and general health in rats given retinolfree diets, but it does not maintain reproduction (Thompson et al. I964) or vision (Dowling \& Wald, 1960). The failure of vision in animals maintained with retinoic acid can be attributed to their inability to convert the acid into the corresponding aldehyde, retinal (Moore, I953), which is known to be the prosthetic group of the visual pigments. The biochemical mechanism which leads to reproductive failure is not understood.

The work reported here has shown that 3 -dehydroretinol, unlike retinoic acid, can maintain reproduction in female rats. It also maintains the structural integrity of the retina and the growth and morphological appearance of the testes of male animals. Previous workers (Shantz \& Brinkman, 1950) have been unable to demonstrate any conversion in vivo of 3 -dehydroretinol into retinol and it therefore seems probable that the 3 -dehydroretinol or the corresponding aldehyde, 3 -dehydroretinal, possesses biological activity per se in vision and reproduction. However, a small conversion into retinol could account for the maintenance of reproduction and vision, and a conclusive demonstration that such conversion does not occur in the rat may require the use of more sensitive analytical methods than have been employed hitherto.

The authors acknowledge the advice and encouragement of Professor D. L. Hughes and Professor R. A. Morton, FRS. They are indebted to Mrs M. W. Harling, AIMLT and Mrs C. McLaughlin for technical assistance and to Mr G. Weston, FIMLT and Mr E. O'Neill for the photographs. 


\section{REFERENCES}

Dowling, J. E. \& Wald, G. (1960). Proc. natn. Acad. Sci., Wash. 46, 587.

Howell, J. McC., Thompson, J. N. \& Pitt, G. A. J. (1963). F. Reprod. Fertil. 5, 59.

Howell, J. McC., Thompson, J. N. \& Pitt, G. A. J. (I964). F. Reprod. Fertil. 7, 25 I.

Millard, E. B. \& McCann, W. S. (I 949). F. appl. Physiol. I, 807.

Moore, T. (1953). Symposium on Nutrition, p. 28. [R. M. Herriott, editor.] Baltimore: Johns Hopkins Press.

Shantz, E. M. (1948). Science, N.Y. I08, 417.

Shantz, E. M. \& Brinkman, J. H. (1950). F. biol. Chem. 183, 467.

Shantz, E. M., Embree, N. D., Hodge, H. C. \& Wills, J. H. Jr (1946). 7. biol. Chem. 163, 455.

Sundaresan, P. R. \& Cama, H. R. (196r). Br. F. Nutr. 15, 225.

Thompson, J. N., Howell, J. McC. \& Pitt, G. A. J. (I964). Proc. R. Soc. B 159, 5 Io.

Wald, G. (I953). Fedn Proc. Fedn Am. Socs exp. Biol. 12, 606.

\section{EXPLANATION OF PLATE}

(a) Retina of a rat fed on the vitamin A-free diet supplemented with methyl retinoate and 3 -dehydroretinol. This is a normal retina. $A$, pigment epithelium; $B$, rod-cone layer; $C$, outer nuclear layer; $D$, inner nuclear layer; $E$, ganglion cell layer. Haematoxylin and eosin.

(b) Retina of a rat fed on the vitamin A-free diet supplemented with methyl retinoate alone. It shows complete loss of the tod-cone layer, and the outer nuclear layer has been reduced to a single row of cells. Haematoxylin and eosin. 

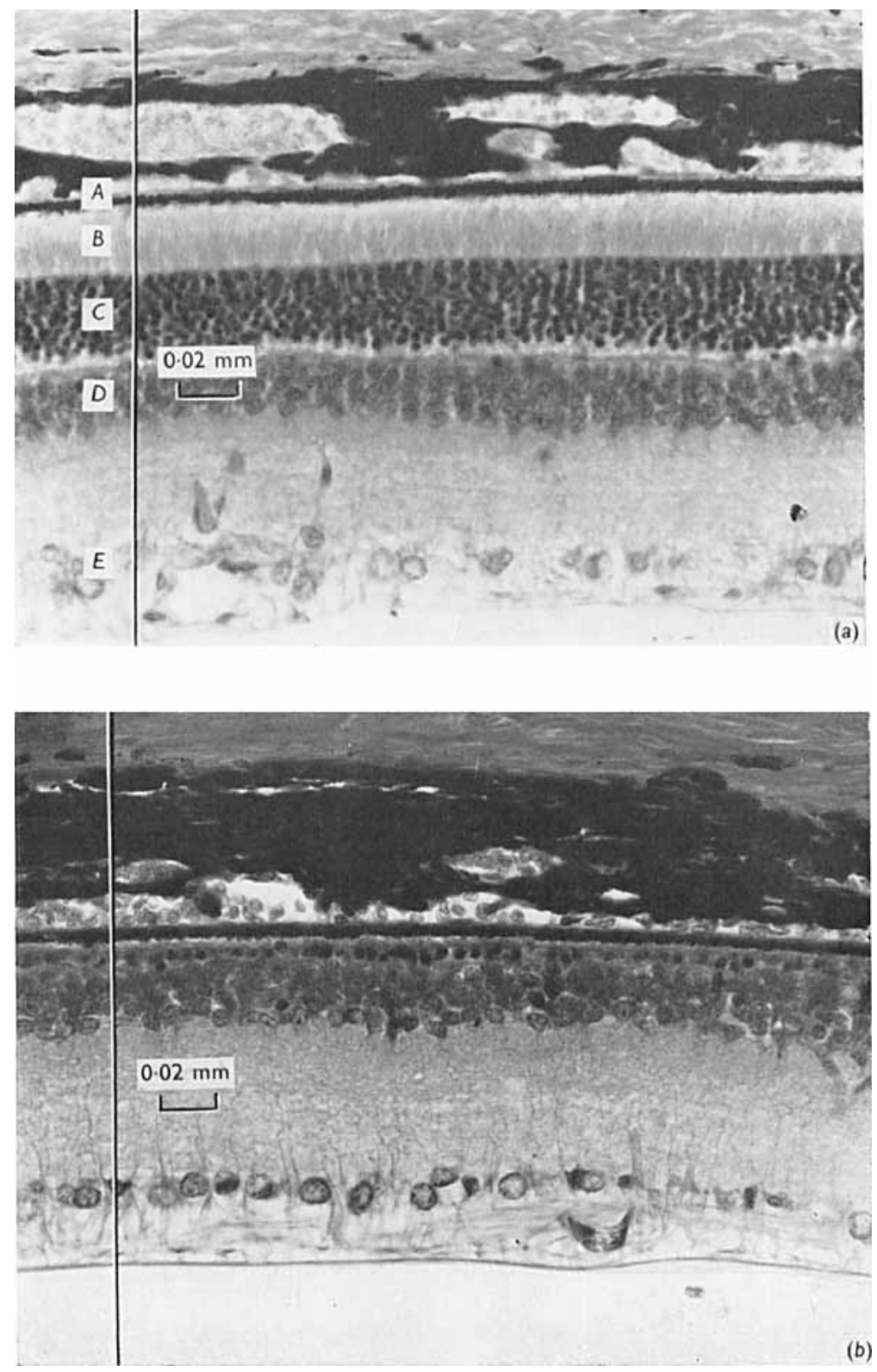

J. McC. HOWELL, J. N. THOMPSON AND G. A. J. PITT 